\title{
LAS APACHETAS DE LOS VIAJEROS. LOS APORTES DE ELENA ALTUNA A LOS ESTUDIOS COLONIALES ANDINOS E HISPANOAMERICANOS CONTEMPORÁNEOS
}

\author{
THE APACHETAS OF THE TRAVELLERS. THE CONTRI- \\ BUTIONS OF ELENA ALTUNA TO THE CONTEMPORARY \\ ANDEAN AND HISPANIC AMERICAN COLONIAL STUDIES
}

\section{AS APACHETAS DOS VIAJANTES. A CONTRIBUIÇÃO DE ELENA ALTUNA AOS ESTUDOS COLONIAIS ANDINOS E HISPANOAMERICANOS CONTEMPORÁNEOS}

\author{
Betina Sandra Campuzano ${ }^{1}$ \\ Universidad Nacional de Salta \\ campuzanobetina@hum.unsa.edu.ar \\ ORCID: 0000-0002-0046-1152
}

Recibido: $10 / 03 / 21$

Aceptado: 20/03/21

1 Profesora en Letras por la Universidad Nacional de Salta, Argentina. Allí, se desempeña como profesora Adjunta en "Literatura Hispanoamericana" y "Problemáticas de las literaturas argentina e hispanoamericana". Estudia el Doctorado en Humanidades, Universidad Nacional de Tucumán. Dirige diversos Proyectos de Extensión Universitaria y el Proyecto de Investigación $\mathrm{n}^{\circ} 2539$ Poéticas migrantes y políticas de la memoria en la literatura y cultura latinoamericanas, radicado en el Consejo de Investigación de la Universidad Nacional de Salta. Es editora responsable de la publicación científica Cuadernos de Humanidades. Coordinó Retratos y atmósferas urbanas (2016) y compiló, junto a Elena Altuna, Vertientes de la contemporaneidad (2016), editados por EUNSa. Publica artículos en revistas científicas nacionales y extranjeras. Integra, como Adjunto Externo, el Grupo de Investigación de Estudios Andinos de Interculturalidad (ESANDINO), Universidad Nacional Mayor de San Marcos, Perú; y el Grupo de Estudios Andinos del Instituto de Literatura Hispanoamericana, Facultad de Filosofia y Letras, Universidad de Buenos Aires, Argentina. 


\section{Resumen}

Me interesa relevar una serie de nociones y categorias que se desprenden del trayecto crítico-teórico de Elena Altuna, cuyos campos fueron la cultura colonial peruana y la literatura hispanoamericana contemporánea. Parto de las lecturas subyacentes en su producción que evidencian el campo intelectual y los cambios de paradigma de su tiempo. Luego, avanzo hacia algunas nociones: el forasterismo que parte de la figura colonial entroncándola con la propuesta cornejo-polariana; la lejanía que, atendiendo a relaciones entre peninsulares y criollos, releva representaciones maceradas en la escritura colonial; retórica del desagravio referida a estrategias escriturarias que, lejos de la mimesis con la metrópolis, manifiestan las resignificaciones de tradiciones ajenas y propias en el contexto criollo; e indio urbano que se ocupa de los cambios entre novela indigenista y testimonio migrante en el sistema literario. Finalmente, me detengo en cómo se configura una constelación de nociones, que contribuye a conformar un yachay quipi (Mamani Macedo, 2019) o saber localizado.

Palabras clave: cultura colonial, criollismo, retórica del desagravio, indio urbano, saber localizado.

\section{Abstract}

It is my aim to focus on a number of notions and categories, which emerge from the critical-theoretical journey of Elena Altuna whose fields of research were the Peruvian colonial culture and the contemporary Spanish-American literature. I will start from the underlying readings in her production which are evidence of the intellectual field and the paradigm shifts of her time. Then, I will advance toward some notions, starting from the notion of foreignness, which copes with the colonial figure, by linking it with the Cornejo-Polarian proposal. Another one is remoteness which, in response to the connections between peninsular and creole people, exposes macerated presentations in colonial writing. Rhetoric of reparation is a notion used to refer to those writing strategies which, far from the mimesis with the metropolis, expose the re-signification of both, the foreign and own traditions in the creole context. The last one is the notion of urban indian, which deals with changes between the indigenist novel and the migrant's testimony in the literary system. Finally, I will focus on the way in which the constellation of notions that contribute to conform a yachay quipi (Mamani Macedo, 2019), or localized knowledge, is configured.

Keywords: colonial culture, creoleism, rhetoric of reparation, urban indian, localized knowledge. 


\section{Resumo}

Interessa-me relevar uma série de noções e categorias que desprendem-se do trajeto crítico-teórico de Elena Altuna, cujos campos foram a cultura colonial peruana e a literatura hispanoamericana contemporânea. Partirei das leituras subjacentes a sua produção que evidenciam o campo intelectual e as mudanças de paradigma do seu tempo. Posteriormente, avançarei rumo a algumas noções: o forasteirismo que parte da figura colonial entroncando-a com a proposta cornejo-polariana; a distância que, atendendo as relações entre peninsulares e crioulos, releva representações maceradas na escrita colonial; retórica do desagravo referida a estratégias escriturais que, longe da mimese com a metrópole, manifestam as resignificações de tradições alheias e próprias no contexto crioulo; e índio urbano que se ocupa das mudanças entre romance indigenista e depoimento migrante no sistema literário. Finalmente, me deterei na maneira como se configura uma constelação de noções, que contribui a conformar um yachay quipi (Mamani Macedo, 2019) ou saber localizado.

Palavras-chave: cultura colonial, criollismo, retórica do desagravo, índio urbano, saber localizado.

Todo el que pasa tiene que poner su piedra.

Ciro Alegría

Podría decirse que Altuna no ha cesado de trajinar junto a esos caminantes que entre los siglos XVI y XVIII recorrieron el mundo andino, $y$ lo construyeron en la realidad y en la representación que de él hicieron en la escritura de un espacio semiótico, prefigurado, y altamente modelizado por las directivas metropolitanas.

Susana Zanetti

\section{Presentación o acerca de la ofrenda de piedra}

Elena Altuna ${ }^{1}$ (San Fernando, Buenos Aires, 1952; Salta, 2016) trajinó los senderos de la docencia y la investigación sobre la cultura colonial peruana y la literatura hispanoamericana contemporánea en la Universidad Nacional de Salta, en el no- 
roeste argentino. Entre sus clases, con las que se iniciaba el cursado, recuerdo especialmente aquella referida al cuento "La ofrenda de piedra" (1969), de Ciro Alegría. Con su voz tanguera, ataviada en tonalidades marrones y verdes, y el cigarrillo en la mano, Altuna cautivaba a la audiencia estudiantil con el relato acerca de un niño blanco, hijo de padre misti y hacendado y de madre de ascendencia indigena, que subía un difícil sendero en la serranía andina junto a un viejo indio, que oficiaba de guía. Allí, los protagonistas encontraban una apacheta: un montículo de piedras que los viajeros andinos van dejando, como ofrendas a la Pacha, cuando emprenden caminos difíciles y encuestados. A pesar del mandato paterno que le prohibía seguir las creencias indigenas a las que consideraba supersticiones, el niño conmovido por la devoción y la dignidad del indio viejo se acerca a las alforjas, toma la piedra y decide finalmente dejar su ofrenda. De este modo, reconoce que su historia es también mestiza. "Transculturada", advertía Altuna a la clase incorporando la presencia de Ángel Rama al análisis. Sobre estas cuestiones nos hablaba con una voz pausada, con ternura y firmeza, arrebatada por momentos, mientras nosotros, sus alumnos, quedábamos sorprendidos del detalle de sus ojos: uno era marrón y el otro, verde.

Esta escena de lectura que aquí formulo no es arbitraria ni fortuita; al contrario, da cuenta de cómo se construye, a partir de la evocación de un archivo, una imagen o una diferencia del sujeto. Tal como advierte Silvia Molloy (2001) al referirse a la autobiografía en Hispanoamérica, una escena de lectura es una práctica narrativa, da cuenta de una biblioteca que escribe un libro y se refiere a otros libros, puede relacionarse con escenas de infancia o iniciáticas, se asocia con la figura de los mentores y puede dar cuenta de cómo se configura la matriz ideológica de una nación. Por ejemplo, a esta intelectual argentina le interesa particularmente cómo, en las escenas de lectura, el sujeto se distancia con respecto al canon europeo por "algo más" que por "ser hispanoamericano" (2001, p. 17). Así, en la autobiografía 
decimonónica de Juan Francisco Manzano se añade el hecho de ser esclavo o en la de Victoria Ocampo, en el siglo XX, la exclusión parcial por ser mujer; lo que empuja a estos sujetos a emplear diversos e ingeniosos recursos en la escritura para lograr la autorrepresentación que desean. Algo de esto, de esas tensiones entre diferentes archivos o lecturas, de producir textos (en este caso, críticos y teóricos) desde espacios regionales (marginales, en muchos casos), puede relevarse no solo en la evocación de tintes autobiográficos que aquí reconstruyo desde mi memoria afectiva y académica, sino también $-\mathrm{y}$, sobre todo- en el mismo trayecto de lecturas que realizó Altuna durante su camino. Sobre este sendero sinuoso, las piedras que se lleva en las alforjas y las ofrendas que se dejan en la apacheta del pensamiento latinoamericano trata este artículo.

Mi propuesta consiste en relevar y sistematizar, a partir de esta escena de lectura, que actúa más bien como una motivación o una excusa, una serie de nociones y categorias que se desprenden del trayecto crítico y teórico de Elena Altuna, pues contribuyen a los campos de los estudios coloniales andinos y literarios hispanoamericanos contemporáneos ${ }^{2}$. Sostengo que la producción crítica y teórica de Altuna da cuenta del modo en que se configura el campo cultural e intelectual (Bourdieu, 1995) y el cambio de paradigma de su tiempo (Adorno, 1988; Altuna, 1999 y 2006), por un lado; por otro, constituye en sí mismo un aporte sustancial para estos ámbitos, pues permite advertir cómo en la escritura se disputan las tradiciones ajenas y las propias. En este sentido, entiendo que la propuesta de Altuna se configura como un saber localizado, un yachay quipi o "bulto del saber" (Mamani Macedo, 2019), pues la autora recoge en sus alforjas una piedra, la lleva hasta el abra y la coloca sobre el montículo de piedras dejadas por viajeros anteriores para señalar el camino. Propongo entonces la metáfora de las apachetas para referirme a este complejo proceso de producción de un conocimiento situado en la región andina, sus vinculaciones con el campo intelectual y los paradigmas literarios, su mirada sobre las continuidades y 
las rupturas en los sistemas regional y continental, y la tensión que se advierte en la escritura entre diversas tradiciones que requieren, de cierta forma, una mirada heterocrómica.

\section{E1 camino y los viajeros: la conformación de un cam- po intelectual}

El cuento de Ciro Alegría pone especial atención en el vínculo que se establece entre el niño y el viejo indio y el modo en que este guía procura convencer al joven viajero, inexperto en el camino andino, sobre la importancia de escoger una buena piedra, llevarla hasta la cima y colocarla junto a las ofrendas de otros viajeros. Es decir, el acento está puesto en el camino o el proceso por el que la puna hace al muchacho más indio. En el mundo andino, la presencia de las apachetas tranquiliza a los viajeros porque les confirma que por esos senderos antes han pasado otros caminantes, que siguen huellas milenarias en muchos casos. En ese ancestral ritual de formar una pirca de piedras, conmovedor y digno, hay además una modificación del paisaje. Bien puede establecerse una analogía con el camino de la crítica y la teoría literarias latinoamericanas que, al igual que los viajeros, circulan empinados recorridos transitados antes por otros caminantes que han dejado sus representaciones, nociones y categorías modificando los campos cultural, intelectual y literario.

Entre algunas de las numerosas y siempre visitadas lecturas subyacentes en la escritura de Altuna, resultan relevantes aquellas que se entroncan en la propuesta de la heterogeneidad y el sujeto migrante $(1982,1994,1996)$ de Antonio Cornejo Polar y los avances que luego señala Raúl Bueno Chávez (2004) dentro de esta línea de la crítica literaria. De la misma manera, Altuna se preocupa por las vinculaciones del polisistema literario continental, por lo que operativiza en diversos momentos la propuesta de las redes de religación (1994) de Susana Zanetti y los planteos de la ciudad letrada (1984) y la transculturación 
narrativa (1984) de Ángel Rama. Zanetti y Rama resultan fundacionales para el abordaje del espesor de los sistemas literarios que coexisten en el continente y las zonas de contacto que interesan a esta crítica literaria.

Con respecto al mundo colonial, espacio de su principal interés, Altuna es deudora de los planteos de Rolena Adorno (1988, 2000) y Walter Mignolo (1982) sobre la situación y el discurso coloniales, pues le permiten organizar el corpus colonial que aborda tanto en El discurso colonialista de los caminantes. Siglo XVII-XVIII (2002) como en Retórica del desagravio (2009). Suscrita en lo que la historiografía ha llamado literaturas de viaje, Altuna construye una serie literaria a partir de textos producidos entre el siglo XVII y XVIII, e inscriptos en el proyecto colonialista. Se ocupa de relevar las construcciones de la territorialidad, las representaciones de los diferentes sectores de la sociedad colonial, las percepciones de la lejanía entre los grupos criollos y la metrópolis, los procedimientos escriturarios que provienen de diferentes tradiciones y que actúan como residuales en muchos casos. Relaciones Geográficas, relatos de viajes, probanzas de méritos, memoriales y cartas de inmigrantes son algunos de los textos culturales en los que Altuna releva las distintas instancias del discurso colonialista que construye una homogeneidad que sustenta, en el plano ideológico, un proyecto politico que perdura hasta hoy.

Completan este panorama las referencias a Michel Foucault de quien recupera la noción de discurso, Roger Chartier de quien retoma la noción de representación, y Raymond Williams de quien toma la categoría de estructura de sentimiento. Otros nombres destacados entre sus interlocutores son Pilar Latasa Vasallo, Raúl Dorra, Carlos García-Bedoya, Miguel Valladares y Amelia Royo, por ejemplo. Por supuesto, esta lista puede omitir involuntariamente nombres que fueron relevantes para la producción de Altuna. Lo que no puede pasar por alto es que este panorama da cuenta del modo en que se construye a fines del siglo XX y la primera década del XXI el campo cultural 
y literario dedicado a los estudios coloniales y latinoamericanistas, desde una región que imbrica formación y lecturas del Cono Sur y los Andes.

De acuerdo con Pierre Bourdieu, el campo social refiere a los "espacios de juego históricamente constituidos con sus instituciones específicas y sus leyes de funcionamiento propias" (Bourdieu citado por Gutiérrez, 1994, p. 21). Estos espacios implican el establecimiento de posiciones que se vinculan con otras posiciones, entablando así luchas dinámicas que conservan o modifican estructuras. El campo literario alude al campo de fuerzas y de luchas perteneciente al espacio social que se organiza en torno a oposiciones (arte puro/ arte burgués) y que además establece una importante relación con el campo del poder. Me interesa dilucidar entonces qué sucede en el campo social y literario a partir de los cambios en la noción de literatura que, advierte Altuna, suceden con el ingreso de los textos de cultura del descubrimiento, la conquista y la colonia, por una parte; y la incorporación de textos híbridos como sucede con los testimonios y las crónicas urbanas, por ejemplo, en la contemporaneidad. En otras palabras, en estas selecciones y abordajes de los que hace eco la producción intelectual altuniana, pueden leerse qué luchas y qué negociaciones se entablan desde espacios regionales de producción del conocimiento, como lo puede ser el Noroeste argentino, con los espacios dominantes de la teoría y la crítica de los ámbitos centrales.

De esta manera, Altuna historiza y sistematiza los cambios de paradigmas en el artículo "Colonialismo: interpretaciones y percepciones" (2006), donde se remonta a la conformación del pensamiento de la descolonización, durante el periodo de postguerra en los años cincuenta, a partir de las producciones de Frantz Fanon, George Balandier y Aimé Cesaire. Así, señala el modo en que el concepto de literatura canónico en América Latina restringido a la reproducción de los modelos metropolitanos es interpelado por una noción más amplia de literatura en los años ochenta, a partir de los planteos de Adorno y Mignolo. 
Previamente, esboza estos supuestos en "Historiografia literaria y estudios coloniales en el pensamiento de Antonio Cornejo polar" (1999), cuando aborda la sistematización del pensamiento cornejo-polariano. Se ocupa entonces del modo en que la incorporación del análisis de las crónicas sobre la escena de Cajamarca, la relectura de los textos del siglo XIX y la revisión de la historiografía literaria peruana permitian al critico peruano ubicar en el centro del debate la noción de literatura y, con ello, su validez para el periodo colonial. Se trataba de abandonar nociones restrictivas y apostar por conceptos más abarcadores, menos condicionados histórico y culturalmente, como pueden serlo las categorias de discurso y práctica social (1999, pp. 124-125).

Este cambio en el paradigma de la disciplina opera en la producción crítica altuniana en sus numerosos estudios sobre los viajeros y caminantes de la colonia, en la conformación de los discursos criollos que evidencian una nueva estructura de sentimiento continental, y en el abordaje al uso de recursos escriturarios propios de la metrópolis que adquieren otros valores y sentidos en la experiencia colonial americana. En otras palabras, la producción de Altuna se mueve entre las tensiones que advierte sagazmente en los textos, en las apropiaciones de procedimientos y directivas metropolitanas y en las autofiguraciones de los criollos. Para ello, emplea tanto herramientas que provienen de la teoría occidental como del pensamiento crítico latinoamericano. Con un enfoque heterocrómico, sistematiza y aborda el corpus colonial andino que, como una apacheta, da cuenta del paso de los viajeros, sus modificaciones del paisaje y sus ofrendas de piedras.

\section{Las apachetas y el conocimiento situado, desde la colonia hasta la contemporaneidad}

“Qué fuera del mundo sin la piedra? Se hundiría. La piedra sostiene la tierra." (Alegría, 1978, p. 29), argumenta el viejo cuando 
el niño cuestiona la devoción. Si continuamos la analogía entre el camino de los viajeros y el de la teoria y la crítica literarias, las apachetas actúan como guías para otros caminantes pues señalan el recorrido y sostienen la tierra. De cierta forma, algo similar sucede con las nociones y categorias que los intelectuales latinoamericanos ofrecen al campo cultural y literario. $\mathrm{Me}$ interesa destacar algunas de las nociones propuestas o reelaboradas por Altuna, que permiten trazar un recorrido desde los tiempos de la colonia hasta los procesos de modernización en el Perú: en esta oportunidad, me centraré en el forasterismo, la lejanía, la retórica del desagravio y el indio urbano.

Como bien se sabe, la figura del forastero en el mundo andino remite a las migraciones internas en la colonia, constituye sin duda una huella cultural ancestral y encuentra en Los ríos profundos (1958) de José María Arguedas, su narrativa por excelencia (Cornejo Polar, 1996; Bueno Chávez, 2004; Noriega Bernuy, 2011). Al igual que Julio Noriega Bernuy, Elena Altuna se ocupa de revistar esta figura tanto a partir del mundo colonial como del rastreo de sus similitudes con el sujeto migrante de Cornejo Polar. Siguiendo a Alfred Schutz, la critica argentina se detiene en la crisis que el forastero sufre como una consecuencia de la ruptura del sistema de significaciones que constituye la pauta cultural del grupo originario. Ello sucede cuando el forastero, que se halla ajeno al grupo de arribo, pretende interpretar el nuevo ambiente social en los términos de su "pensar habitual”. La carencia de status dentro del nuevo grupo, la imposibilidad de establecer una vía de transformación entre los esquemas culturales, el hallarse fuera de su territorio propio le producen una dislocación de sus procesos de significatividad que lo asemejan a la condición del sujeto migrante considerada por Cornejo Polar. Altuna explica, al igual que el crítico peruano, que no se trata "de sumar nuevas categorias a las ya existentes, sino de complejizar la imagen de un sujeto unitario y autorreflexivo legada por el romanticismo, que espejeaba como horizonte de una modernidad empeñada —en el ámbito de los 
discursos críticos- en buscar una identidad homogénea" (Altuna, 1999, p. 125).

Altuna recupera las posiciones múltiples que pueden hallarse en el discurso de forasteros en la colonia y migrantes en la modernidad contemporánea; por ello, se interesa por sistematizar las propuestas cornejo-polarianas y trazar su operatividad en los estudios coloniales. Advierte que el referente peruano no abordó específicamente un corpus colonial con la categoría del sujeto migrante, pero sí encontró una matriz fundadora en la figura de Felipe Guaman Poma de Ayala y el acápite "Camina el autor". De esa forma, Cornejo Polar inauguró la posibilidad de analizar un abanico de discursos: por ejemplo, en los relatos de viaje del siglo XVII, Altuna observa cómo se diseña la figura de caminantes escindidos entre sus múltiples memorias; o en las cartas de los inmigrantes a Indias, la crítica argentina se detiene en cómo se construye la "diferencia" colonial a partir de la lejanía de los criollos con los centros metropolitanos, estableciendo un "acá" y un "allá" que será fundamental para el criollismo (Altuna, 1999, pp. 126-127).

El concepto de lejanía resulta sin duda una de las piedras centrales en el pensamiento crítico de Altuna. Con él, se refiere a las polémicas entre criollos y peninsulares atravesadas por las tensiones entre lo periférico y lo central, entre el "aquî" y el "alli", que se hallan maceradas en la escritura donde se confrontan tanto los textos como las representaciones que un grupo tiene de sí y de los otros $(2009$, p. 101). Altuna captura en los textos coloniales peruanos una estructura de sentimiento o un clima de época: los grupos criollos perciben su situación de lejanía en relación con la península y ello les genera una peculiar experiencia de extrañamiento, a la que la crítica argentina entiende como la "diferencia americana". El modo en que se percibe la periferia a sí misma en las colonias incide en las representaciones de los diferentes sectores que habitan el territorio peruano (españoles acriollados, criollos, indios, mestizos, por ejemplo), que generan reivindicaciones, acusaciones 
y resentimientos entre ellos. A su vez, se originan alianzas y confluencias que, lejos de diluir las fronteras, acentúan las diferencias étnicas e intergrupales.

El colonialismo produce estereotipos que abonaban la diferencia americana. Para contrarrestarlos, los letrados criollos se preocupan por elaborar un contradiscurso que dé cuenta de una autoconciencia colonial que oscila entre el resentimiento y la reivindicación; que modela aliados y prevé las réplicas; y que distingue entre hijos propios, extranjeros y advenedizos. Se trata de desplegar una argumentación que convenza a los peninsulares de la paridad con los nacidos en la colonia; para ello, los letrados criollos buscan las estrategias escriturarias que les permiten acortar la lejanía con la metrópolis. Así, Altuna diseña la noción de retórica del desagravio para referirse al modo en que "los coloniales idearon estrategias escriturarias sumamente complejas, pues en su interior operaban tradiciones propias y ajenas, en procesos residuales de riquísima creatividad." (2009, p. 18). Dicho de otra manera, Altuna observa el modo en que la escritura de los letrados criollos recupera elementos propios de las retóricas y las estéticas metropolitanas que se afirman en concepciones eurocéntricas modernas, y las resignifican a partir de su experiencia americana y las tradiciones continentales para dar cuenta de las demandas, las aversiones y las reivindicaciones de su sector.

Subyace en esta propuesta una evidente metodología que desmantela aquellos enfoques que reducen el mundo colonial a una consecuencia o un espejo del imperio. En cambio, introduce las modulaciones del sector criollo, sus alianzas y sus detractores, sus sentidos de pertenencia y sus posiciones de privilegio en la colonia. Así, el abordaje a los memoriales que poseen una triple función (representar, informar y manifestar), a los registros satíricos que denuncian el avance de extranjeros y advenedizos, y a la denuncia de agravios que asume la representatividad de los indígenas, da cuenta de cómo "las valencias de la lejanía y la cercanía del poder metropolitano inciden en la 
producción de los letrados coloniales, y dejan su impronta en las estrategias representacionales" (2009, p. 112).

De otra parte, Altuna se preocupa por abordar las tensiones entre los sistemas literarios regional y continental, sus contactos y los elementos residuales que comunican a los sistemas entre sí. Siguiendo la teoría cultural de Raymond Williams, la critica literaria se interesa por los cambios o las rupturas en el sistema o en la hegemonía, pues considera que se trata de una tendencia no totalizadora en la que intervienen diferentes tensiones. Por eso, entre otros temas y otros corpus, en el artículo "La partida inconclusa: indigenismo y testimonio" (2008), se ocupa particularmente de las relaciones entre el indigenismo literario andino y el testimonio contemporáneo, tomando como punto de confluencia entre ambas propuestas las migraciones campesinas a los centros urbanos que se producen en la segunda mitad del siglo XX (Altuna, 2008). En esta ocasión, revista la noción cornejo-polariana del sujeto migrante para observar en qué grado esta incide en la transformación del sistema indigenista y en la consolidación del género testimonial. Altuna explicita su posicionamiento al inscribirse en el ámbito de los estudios culturales latinoamericanos y al evidenciar la operatividad en sus estudios de las categorias literarias de Cornejo Polar y las reformulaciones de Bueno Chávez: "Esta rápida mención al marco teórico-crítico del que me nutro permite (al menos eso espero) plantear la noción de cambio en sistemas históricamente situados, permeables y dinámicos” (2008, p. 121).

Así, después de realizar un recorrido por la reflexión acerca del indigenismo como sistema que se halla en la escritura de José Carlos Mariátegui en Siete ensayos de interpretación de la realidad peruana (1928), y de delimitar un indigenismo canónico caracterizado como "ortodoxo" por Tomás Escajadillo, "heterogéneo" por Antonio Cornejo Polar y “epigonal” por Rubén Bareiro Saguier; Altuna se detiene en los efectos de las migraciones campesinas que arriban a las urbes costeñas como un tema nuevo que irrumpe en la narrativa peruana. Siguiendo 
a Tomás Escajadillo, advierte que el corrimiento de foco hacia los migrantes permite vislumbrar una transformación del referente del indigenismo; novedad esta que puede significar un cambio sistémico (2008, p. 124). Por eso, propone considerar al migrante como un elemento que pasa de la serie socioeconómica a la serie literaria. De allí que proponga la categoría del indio urbano $^{3}$ que modifica los conceptos del campesino y el colono; ello "sugiere que otras transformaciones (además de la del referente) están operando en el sistema: la fractura de la ideología espacial colonizadora: campo versus ciudad y las modalidades sociolingüísticas que, en definitiva, arrastran la problemática hacia el plano de las estructuras novelísticas" (2008, p. 124).

En este recorrido, contribuyen al cambio sistémico tanto las novelas Los ríos profundos (1958) y El zorro de arriba y el zorro de debajo (1971) de José María Arguedas a partir de la figura de los forasteros, como el testimonio urbano Taquile en Lima. Siete familias cuentan... (1986) de José Matos Mar a partir del relato polifónico de dos generaciones de migrantes que arriban de la isla a la urbe limeña. Para esta intelectual argentina, es posible entonces hablar de un indigenismo urbano ${ }^{4}$ que es producto del testimonio del migrante en la medida en que puede observarse una transformación de la heterogeneidad, producto de la migración. Se trata de "un caso de adelgazamiento del término 'indigenismo' a favor del rasgo predominante de la migración: la presencia de dos lugares incorporados a la existencia del sujeto y que coexisten en la memoria y en la práctica diaria de la supervivencia" (2008, p. 137).

Sobre estos planteos quiero destacar dos asuntos: en efecto, Altuna se ocupa del espesor del sistema literario, en términos de Ángel Rama (1994), pero no solo porque encuentre las continuidades y los cambios entre el indigenismo canónico y el urbano o testimonial, sino también -y, sobre todo- porque está revistando la figura del forastero y del migrante desde la colonia misma advirtiendo sus transformaciones históricas tanto en la serie socioeconómica como en la literaria. Luego, la propuesta 
de Altuna en este tramo de su trayecto da cuenta de un interés particular por la historiografía literaria latinoamericana que la empuja a abordar la simultaneidad de sistemas y las luchas entre sus tendencias no solo en el ámbito de los estudios andinos sino también en los latinoamericanistas.

Este interés por los criterios historiográficos recorre también los últimos tiempos de Altuna, tanto en su tarea docente como investigativa; lo que genera la compilación Vertientes de la contemporaneidad. Géneros híbridos y nuevas subjetividades en la literatura latinoamericanas (Altuna y Campuzano, 2016) que reúne las continuidades y los cambios en el sistema literario continental. Frente a la dificultad de acceso a los estudios historiográficos producidos y editados en Estados Unidos, Canadá y España, cuya circulación resulta ajena para estudiantes y docentes de universidades como las del Noroeste argentino, y que legitiman un sistema crítico propio, hermético y autosuficiente; frente a la ausencia de nuevas perspectivas de nuestras literaturas que logren escapar de las tendencias de otras agencias, como resultan los estudios de la subalternidad o de las minorías étnicas; y frente a los problemas presupuestarios que no permiten el desarrollo de un pensamiento situado sino que contribuyen a la percepción de que nos conformamos como el "objeto" que es admirado o contemplado por otros (Campuzano, 2016), la propuesta de elaborar una historiografia propia sobre el sistema literario continental reciente tomó impulso en esta compilación que es situada, provisoria y mejorable. También, resulta inconclusa como lo es la partida de los migrantes serranos que recorrieron tanto los Andes y la costa, como las lecturas y las escrituras de Altuna.

\section{A modo de conclusión: hacia la construcción del ya- chay quipi (el bulto del saber)}

Frente a la importación de herramientas y teorias foráneas que asumen las comunidades académicas regionales y continenta- 
les, Mauro Mamani Macedo (2019) propone indagar categorias y metáforas andinas para abordar las producciones en lenguas indígenas o que den cuenta de una visión de mundo andina. Se trata de proponer un saber nativo que dialogue con el saber forastero y evitar las reducciones y los juicios peyorativos que, al igual que el padre del niño de "La ofrenda de piedra", consideran el conocimiento de estas tierras como una mera creencia, una superstición, una palabra embrujada. Frente al purun yachana (un saber salvaje), el académico quechua y aymara propone advertir la existencia del yachay quipi (bulto del saber) para referirse al conocimiento que imbrica pensamiento y sentimiento en los Andes y que coexiste con el pensamiento científico. Emplea para ello la metáfora del bulto o el atado que el runa lleva amarrado en su espalda.

En el cuento de Ciro Alegría, el narrador concluye: "Simbólicamente acaso, ese mundo de piedra estaba allí, al pie de la cruz, en las ofrendas de miles de cantos, de piedras votivas, llevadas a lo largo del tiempo, en años que nadie podía contar, por los hombres del mundo de piedra" (1978: 32). Hay aquí una potente imagen en estos caminantes andinos que pertenecen a diferentes mundos y tradiciones, y que tienen diferentes saberes: las piedras que cargan en sus alforjas se añadirán a la apacheta, a una ofrenda que es ancestral y que reúne el paso de otros caminantes por el mismo recorrido. Sin duda, esta puede ser una metáfora generada en la visión de mundo y la experiencia andinas para referirnos tanto al trayecto de los campos culturales y literarios de nuestra macrorregión, como a la constelación de nociones que pueden relevarse de la producción crítica y teórica de Elena Altuna. De esta forma, se configura un saber localizado que lee las producciones peruanas y latinoamericanas con mirada heterocrómica, con la tradición de la academia occidental y la experiencia y los saberes andinos y latinoamericanos, con las representaciones de la lejanía y de la cercanía en relación con las metrópolis, con la denuncia políti- 
ca y social de los indigenistas y la escisión de los indios urbanos en los testimonios, por ejemplo.

Altuna revista categorias que provienen de la colonia, como la del forastero, y las resignifica en las textualidades contemporáneas atendiendo a las matrices que en ellas encuentra; se preocupa por ampliar las nociones canónicas y poner en entredicho las reglas metropolitanas; se encarga de trazar las continuidades y las transformaciones tanto en las series socioeconómicas como en las literarias; se interesa por desmontar las operaciones ideológicas y escriturarias que colonizan y releva los contradiscursos que generan para resistirlas o para revitalizarlas. Para quienes transitamos por sus aulas, sus proyectos y sus lecturas, sabemos que esta viajera de mirada heterocrómica ha trajinado, como sugiere Zanetti, junto a sus caminantes coloniales y ha dejado su piedra en la apaecheta.

Tras las huellas de Elena Altuna

Marzo de 2021

\section{Notas}

1 Elena Altuna fue Profesora, Licenciada y Doctora en Letras. Trabajó en la Universidad Nacional de Salta, donde estuvo a cargo de Literatura Hispanoamericana y Problemáticas de las literaturas argentina y latinoamericana. Dirigió proyectos radicados en el Consejo de Investigación de la Universidad Nacional de Salta. Publicó El discurso colonialista de los caminantes (siglos XVII-XVIII) (Berkeley, Latinoamericana Editores, 2002) y Retórica del desagravio (Salta, CEPIHA, 2009). Coordinó y editó "Viajes y viajeros coloniales por las Américas", en la Revista de Crítica Literaria Latinoamericana $n^{\circ} 60$, año XXX (Lima-Hanover, New Hampshire). Tuvo varios libros en colaboración y compiló volúmenes colectivos. Fue Becaria de la John Carter Brown Library, en Brown University, Providence, Rhode Island.

2 Este artículo sistematiza y amplía la exposición solicitada para el Seminario Tinkuy de lecturas sobre literaturas y culturas andinas, a cargo de Florencia Angulo y organizado por las cátedras de Literatura I y Literatura II del Profesorado y Licenciatura en Letras, Facultad de Humanidades y Ciencias Sociales, Universidad Nacional de Jujuy, durante el año 2020 y a través de la modalidad virtual.

3 Entiendo que la categoría de indio urbano resulta efectivamente operativa para el abordaje de otros corpus literarios o culturales que estén atravesados por la visión y la experiencia indigena. Así, luego de leer el prólogo de 
Elena Altuna al poemario Nadie se cruza de bando (2010), del poeta salteño Jesús Ramón Vera, y adscribiéndose al paradigma de las literaturas heterogéneas de Antonio Cornejo Polar, Pamela Rivera (2014) propone hablar de indio urbano para referirse a la experiencia dislocada del comparsero que se configura en la obra de Vera. El fragmento que Rivera recupera de Altuna sugiere la categoría, aunque no la enuncia necesariamente como tal: "...el tono marcadamente social que la poesía de Jesús Ramón Vera expresa en sus inicios, persiste en Nadie se cruza de bando Nadie se cruza de bando y se abre hacia los sectores marginados que pueblan la ciudad contemporánea. Lo que aquí se intensifica, en todo caso, es la conciencia desgarrada de la finitud" (Altuna citada por Rivera, 2014, p. 20).

4 Cornejo Polar sugiere hablar de indigenismo urbano en el artículo "La literatura peruana e identidad nacional: tres décadas confusas" (1995), para señalar la cuestión de las identidades (el hispanismo, el mestizaje, el indigenismo) como falsos problemas que son construidos por una elite intelectual y son puestos en entredicho por la presencia de los migrantes en las ciudades. Altuna no refiere a este texto porque, probablemente, no lo haya conocido; pero las lineas y las conclusiones a las que arriban ambos escritos son sin duda similares o dan cuenta, justamente, de las preocupaciones del campo literario peruanista de entre siglos.

\section{Referencias bibliográficas}

Adorno, R. (1988). Nuevas perspectivas en los estudios literarios hispanoamericanos. Revista de critica literaria latinoamericana. Año XIV, n 28, 11-27.

-. (2000). La pertinencia de los estudios coloniales para el nuevo milenio. Andes $n^{\circ} 11$. https://www.redalyc.org/comocitar. oa? id $=12701102$

Alegría, C. (1978) [1969]. La ofrenda de piedra. Buenos Aires: Losada.

Altuna, E. (1999). Historiografia literaria y estudios coloniales en el pensamiento de Antonio Cornejo Polar. Revista de crítica literaria latinoamericana. Ano XXY, n50, 121-129.

- (2002). El discurso colonialista de los caminantes. Siglos XVII-XVIII. Michigan: Centro de Estudios Literarios "Antonio Cornejo Polar" (CELAP) y Latinoamericana Editores.

- (2006). Colonialismo: interpretaciones y percepciones. Katatay. Año II, n 3/4, 58-65. 
-. (2008). La partida inconclusa: indigenismo y testimonio. Revista de crítica literaria latinoamericana. Año XXXIV, $n^{\circ} 68$, 121-141.

- (2009). Retórica del desagravio: estudios de cultura colonial peruana. Salta: CEPHIA, Universidad Nacional de Salta.

-. (2010). Apto para intemperie. En Vera, J.R. Nadie se cruza de bando. Salta: Verdor y Verdin, 5-10.

Arguedas, J.M. (1971). El zorro de arriba y el zorro de abajo. Buenos Aires: Losada.

—. (1986) [1958]. Los ríos profundos. Caracas: Ayacucho.

Bourdieu, P. (1995). Las reglas del arte. Génesis y estructura del campo literario. Barcelona: Anagrama.

Bueno Chávez, R. (2004). Antonio Cornejo Polar y los avatares de la cultura latinoamericana. Lima: Universidad Nacional Mayor de San Marcos.

Campuzano, B. (2016). Prólogo. En Altuna, E. y Campuzano, B. (comps.). Vertientes de la contemporaneidad. Géneros híbridos y nuevas subjetividades en la literatura latinoamericana. Salta: Editorial de la Universidad Nacional de Salta.

Cornejo Polar, A. (1994). Escribir en el aire. Ensayo sobre la heterogeneidad sociocultural en las literaturas andinas. Lima: Horizonte.

-. (2013 [1982]). Sobre literatura y crítica latinoamericanas. Lima: Centro de Estudios Latinoamericanos Antonio Cornejo Polar.

- (1995). La literatura peruana e identidad nacional: tres décadas confusas. En J. Cotler, (ed.). Perú 1964-1994. Economía, sociedad y política. Lima: Instituto de Estudios Peruanos, 294302.

-. (1996). Una heterogeneidad no dialéctica: sujeto y discurso migrantes en el Perú moderno. Revista Iberoamericana. Vol. LXII, n' $176-177,837-844$.

Gutiérrez, A. (1994). Pierre Bourdieu: las prácticas sociales. Buenos Aires: Centro Editor de América Latina.

Mamani Macedo, M. (2019). Purun Yachana. El valor de las categorias culturales andinas en la explicación de nuestra literatura. Jornaler@s, Año 4/ n 4, 11-22. http://www.fhycs.unju. 
edu.ar/documents/publicaciones/revistas/jornales4/MAMAN\%C3\%8D\%20MACEDO-Conferencia-\%20Purun\%20Yachana.pdf

Mariátegui, J.C. (2000) [1928]. Siete ensayos de interpretación de la realidad peruana. Lima: Empresa Editora Amauta.

Matos Mar, J. (1986). Taquile en Lima. Siete familias cuentan... Lima: Fondo Internacional para la Promoción de la Cultura, UNESCO- Banco Internacional del Perú.

Mignolo, W. (2008) [1982]. Cartas, crónicas y relaciones del descubrimiento y de la conquista. En Iñigo-Madrigal, L. (coord.). Historia de la literatura hispanoamericana. Tomo I. Madrid: Cátedra, 57-116.

Molloy, S. (2001). Acto de presencia. La escritura autobiográfica en Hispanoamérica. México: Fondo de Cultura Económica.

Noriega Bernuy, J. (2011). El forastero andino en Los ríos profundos. En Flores Heredia, G.; Morales Mena J. y Martos Carrera, M. (eds.). Arguedas Centenario. Lima: Universidad Nacional Mayor de San Marcos, 152-162.

Rama, Á. (1984). La ciudad letrada. Montevideo: Arca.

—. (2008 [1984]). Transculturación narrativa en América Latina. Buenos Aires: Ediciones El Andariego.

- (1994). Los guachipolíticos rioplatenses. Volumen 1. Buenos Aires: Centro Editor de América Latina.

Rivera Giardinaro, P.R.A. (2014). El indio urbano en la poética de Jesús Ramón Vera: desplazamientos. Salta: Fondo Editorial de la Secretaría de Cultura de la Provincia de Salta.

Zanetti, S. (1994). Modernidad y religación: una perspectiva continental (1880-1916). En Pizarro , Ana (comp.). América Latina: Palavra, Literatura e Cultura. Vol. II. Sao Paulo: Campinas-Unicamp, 489-534. 